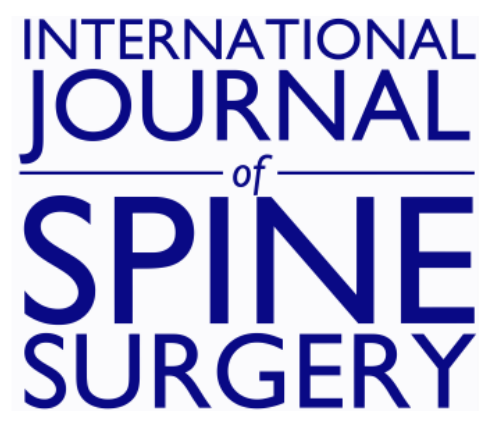

\title{
Effect of Protein Supplement on Paraspinal Muscles in Spine Fusion Surgery: A Randomized, Double-Blind, Placebo-Controlled Trial
}

Razieh Khalooeifard, Zahra Vahdat Shariatpanahi, Amirahmad Ahani, Mohsen Keykhaee, Maryam Oraee-Yazdani, Alireza Zali and Saeed Oraee-Yazdani

Int J Spine Surg 2021, 15 (1) 47-54

doi: https://doi.org/10.14444/8005

http://ijssurgery.com/content/15/1/47

This information is current as of April 26, 2023.

Email Alerts Receive free email-alerts when new articles cite this article. Sign up at: http://ijssurgery.com/alerts 


\title{
Effect of Protein Supplement on Paraspinal Muscles in Spine Fusion Surgery: A Randomized, Double-Blind, Placebo-Controlled Trial
}

\author{
RAZIEH KHALOOEIFARD,${ }^{1}$ ZAHRA VAHDAT SHARIATPANAHI, ${ }^{1}$ AMIRAHMAD AHANI, ${ }^{2}$ MOHSEN \\ KEYKHAEE, ${ }^{2}$ MARYAM ORAEE-YAZDANI, ${ }^{2}$ ALIREZA ZALI, ${ }^{2}$ SAEED ORAEE-YAZDANI, MD ${ }^{2}$ \\ ${ }^{I}$ Department of Clinical Nutrition and Dietetics, Faculty of Nutrition and Food Technology, Shahid Beheshti University of Medical Sciences, Tehran, Iran, \\ ${ }^{2}$ Functional Neurosurgery Research Center, Shohada Tajrish Comprehensive Neurosurgical Center of Excellence, Shahid Beheshti University of Medical Sciences, \\ Tehran, Iran
}

\begin{abstract}
Background: Dysfunction and weakness due to atrophy of the paraspinal muscles is a major issue after posterior spinal fusion (PSF) surgery, resulting in pain and disability. Considering the role of protein in muscle regeneration, it seems that protein supplements after surgery may prevent muscle atrophy. To date, to our knowledge, no intervention study has investigated the effect of protein supplementation on the volume of paraspinal muscles, pain, or disability after PSF.

Methods: In this randomized, double-blind, placebo-controlled clinical trial, patients were randomly assigned to a control (placebo + diet with $1.2 \mathrm{~g} / \mathrm{kg}$ body weight of protein, $\mathrm{n}=40)$ or a protein supplementation $(36 \mathrm{~g} / \mathrm{day}+\mathrm{a}$ diet with $1.2 \mathrm{~g} / \mathrm{kg}$ body weight of protein, $\mathrm{n}=40$ ) group, which received intervention from 48 hours before to 1 month after surgery. The cross-sectional area (CSA) of the paraspinal muscles was measured by thin-slice computed tomography, and pain and disability were assessed using the visual analog scale and Oswestry Disability Index.

Results: After 4 weeks of protein supplementation, the CSAs of multifidus and psoas muscles on both sides were significantly higher in the supplementation group than the placebo group $(P<.001)$. Less atrophy was seen in the right erector spinae and quadratus lumborum muscles in the group receiving protein supplements than the placebo group $(P$ $<.001)$. In addition, protein supplementation was significantly negatively correlated with both pain $(P<.001)$ and disability $(P<.001)$.

Conclusions: In conclusion, we demonstrated that $36 \mathrm{~g} /$ day protein supplementation significantly increased the CSA of muscles and reduced the atrophy, pain, and disability after PSF surgery.
\end{abstract}

Level of Evidence: 2.

Lumbar Spine

Keywords: muscle atrophy, spine surgery, visual analog scale

\section{INTRODUCTION}

Spine fusion surgery is a type of surgery in which 2 or more vertebrae are fixed. The purpose of this surgery is to eliminate pain, instability, and other symptoms of disease by restricting movement between the vertebrae. ${ }^{1-3}$ Many studies have reported mechanical and physiological changes after surgery that lead to adverse problems, such as accelerated destruction of adjacent tissues, pseudarthrosis, or chronic low back pain. ${ }^{4-7}$ Changes reported in the paraspinal muscles after surgery include muscle atrophy, edematosis, changes in adipose tissue, and decreased muscle potential. The prevalence of such injuries is high after posterior spinal fusion (PSF). ${ }^{8,9}$ The paraspinal muscles, including the psoas, multifidus, erector spinae, and quadratus lumborum, maintain the stability of the spine. ${ }^{10}$ Surgery creates catabolic conditions in which proinflammatory and inflammatory factors are secreted, and subsequent inflammation reduces lean body mass (LBM). In addition, PSF creates an additional load on the surfaces adjacent to the fusion sections, which increases the risk of instability and degeneration in these surfaces. Lumbar muscle atrophy and increased muscle tissue fat have negative effects on the patient's recovery. ${ }^{11-13}$

It has been shown that up to $20 \%$ of muscle mass in the operative limb can be lost between 10 and 21 days after surgery. With disuse, the load-bearing 
extremity triggers a set of metabolic processes that lead to muscle atrophy. Muscle atrophy causes a loss of muscle strength, which can have a serious impact on the speed and quality of recovery. ${ }^{14}$ All fusion methods, including anterior and posterior fusion of the spine, cause muscle damage and subsequent atrophy. ${ }^{15}$ The important role of dietary protein in minimizing this complication has been overlooked. The role of proteins in the metabolism of muscle cells is essential. Protein maintains muscle mass by providing building blocks for new tissue in the form of amino acids. Consuming enough protein along with the body's natural secretion of hormones, such as growth factors, insulin, and testosterone, helps to rebuild and grow muscle. ${ }^{16}$

The use of a protein supplement in spine fusion surgery can prevent paraspinal muscle atrophy by maintaining muscle mass, regeneration, and muscle growth. By reducing the rate of pseudoarthritis, pain, and disability, it can also have a positive effect on the patient's recovery. Despite numerous studies showing the effects of protein on muscle formation and health, no experimental or clinical studies have examined the effect of protein supplementation on paraspinal muscle condition in spine fusion surgery. The aim of this study was to evaluate the effect of protein supplementation in lumbar spine fusion surgery on the volume of paraspinal muscles, pain, and disability after PSF.

\section{MATERIALS AND METHODS}

\section{Patients}

This was designed as a double-blind, randomized, placebo-controlled study in patients scheduled for elective lumbar PSF surgery from Feb 2019 to Jun 2020 at Shohada Tajrish Hospital, Tehran, Iran. We excluded patients who were younger than 18 years of age or older than 65 years, body mass index $(\mathrm{BMI})<18.5$ or $>30$, those with a history or current diagnosis of severe liver or kidney disease, diabetes, gastrointestinal malabsorption, parathyroid gland disorders, neuromuscular diseases, such as dystrophies or neurological disorders (multiple sclerosis, amyotrophic lateral sclerosis, etc), osteoporosis, myopathy, smoking, history of trauma and fracture of the vertebral, and allergy or intolerance to protein or placebo supplement. Flowchart for patients who have inclusion criteria for the study is given in Figure 1. The study protocol was approved by the Ethics Committee of Shahid
Beheshti University of Medical Sciences (IR.SBMU.RETECH.REC.1398.802) and registered under the code numbers of NCT04300517 at ClinicalTrials.gov and IRCT20200301046655N1 at the Iranian Registry of Clinical Trials. Informed consent was obtained from all participants. To determine the sample size, we conducted a small pilot study with 10 patients in each group because we did not find a related study about our objective. The minimum sample size estimated for each group was 25 at a power $(1-\beta)$ of $80 \%$ and $\alpha=.05$ for a 2 -arm parallel study with the frequency of $40 \%$ and $70 \%$ for rate of atrophy of paraspinal muscles in the protein supplement and control groups, respectively, obtained from the pilot study.

\section{Interventions}

The patients were randomized to receive either the intervention or placebo supplement. Supplements in both groups had the same taste and were provided in identical packaging. Randomization of the patients was done by applying a table of random numbers. The patients and investigators were all blinded to the study groups. The intervention group received $36 \mathrm{~g} /$ day of protein supplement (Karen Pharma and Food Supplement Co, Iran) equivalent to 3 sachets of pure protein from 48 hours before surgery to 1 month after surgery; each sachet contained $12 \mathrm{~g}$ of protein, $1 \mathrm{~g}$ of carbohydrates, $0.4 \mathrm{~g}$ of fat, $58 \mathrm{kcal}$ of energy. The placebo group received 3 sachets of Carbo Mass powder (Karen Pharma and Food Supplement Co, Iran) daily from 48 hours before surgery up to 1 month after surgery; each sachet contained $5 \mathrm{~g}$ of carbohydrates, $0 \mathrm{~g}$ of protein, $0 \mathrm{~g}$ of fat, $20 \mathrm{kcal}$ of energy.

\section{Data Collection and Analysis}

Our primary outcome was assessing the crosssectional area (CSA) of paraspinal muscles as an indicator of muscle volume change between the 2 groups. Secondary outcomes were the rate of pain and disability between the 2 groups after surgery.

In both groups, anthropometric measurements, including height; weight; and BMI before surgery, 1 month, and 3 months after surgery, were measured. Bone mineral density (BMD) was assessed by dual $\mathrm{x}$-ray absorptiometry. BMD was measured at the lumbar spine (anteroposterior and lateral views) and the contralateral proximal femur (femoral neck and trochanter). Osteopenic patients ( $\mathrm{T}$ score $>-1)$ were excluded from the study. Patients' nutritional 


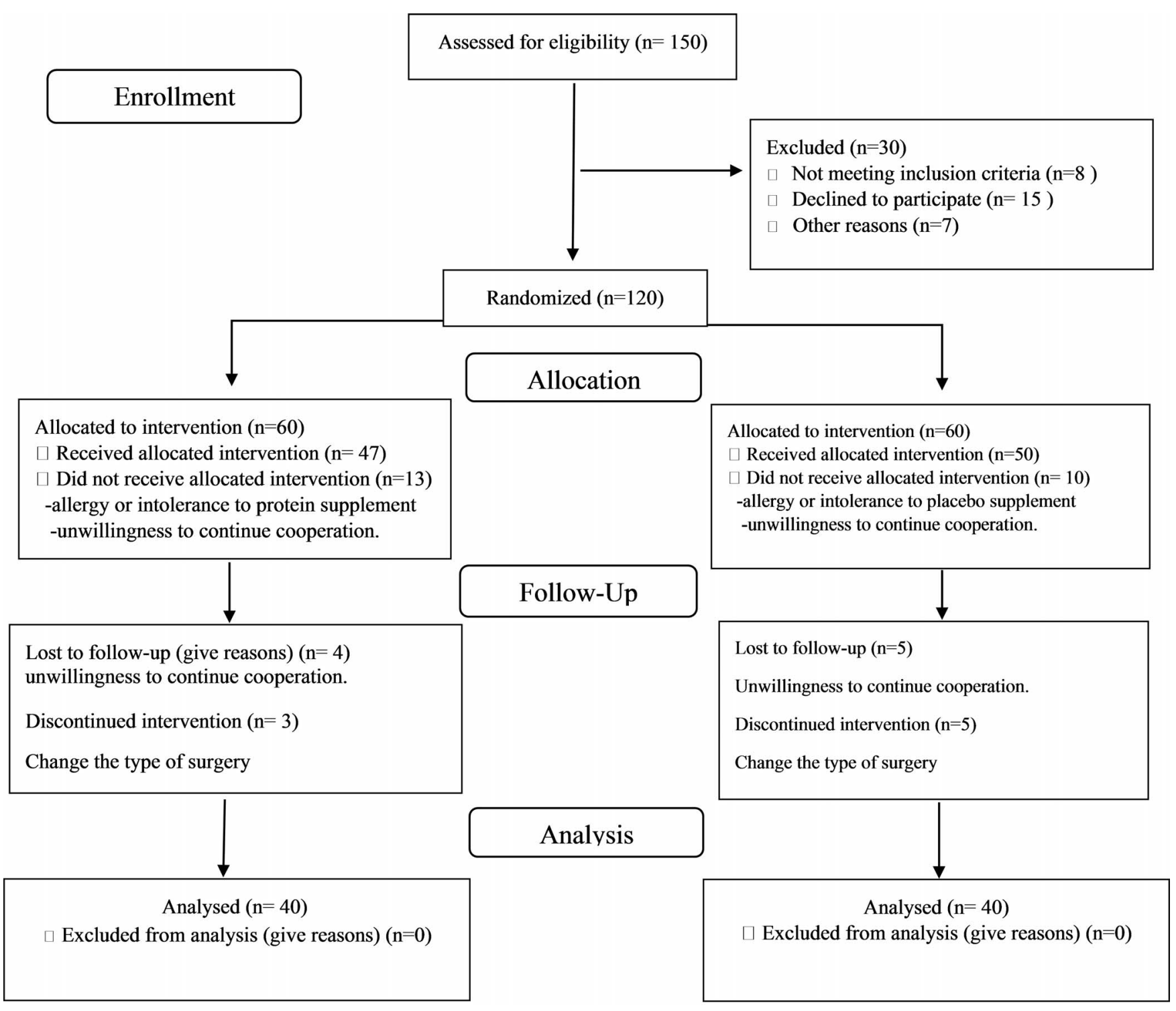

Figure 1. Consolidated Standards of Reporting Trials flow diagram.

intake status was assessed before surgery, 15 days, 1 month, and 3 months after surgery, by a 24-hour recall (an average of 3 days: 1 day off and 2 normal days for each time) through an interview by the researcher. Nutrition 4 software (version 3.5.2; N4, USDA). was used to analyze food intake. Also, by telephone follow up, patients were examined every week for 3 months after surgery for diet and supplementations.

For the analysis of paraspinal muscle volume, we measured CSA of multifidus, psoas, erector spinae, and quadratus lumborum muscles the day before operation and 90 days after surgery using thin-slice computed tomography (CT) scans above fused segments to exclude metal artifacts. Region of interest (ROI) on preoperative and postoperative
CT was measured using PACS workstation (Viewrex, Seoul, Korea). For the measurement of CSA of the muscles, care was needed to not include fat or bones around it, and ROI of the muscles was measured at the lowest level above a fused segment (Figure 2). ${ }^{17-19}$ CT images were evaluated by 2 blinded persons including a radiologist and a neurosurgeon independently. The cross section of muscles was measured bilaterally, and its mean was calculated at each side for each muscle. Pain at the lower back and pelvis was assessed by visual analog scale (VAS) in 2 groups at preoperation, the time of discharge, day 15, 1 month, and 3 months after surgery. Also, the Oswestry Disability Index (ODI) questionnaire was used to evaluate disability at preoperation, 1 month, and 3 months after surgery 


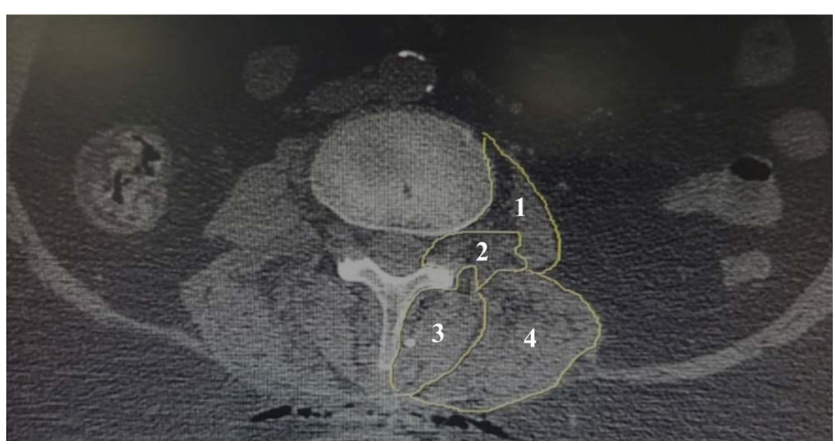

Figure 2. Measurement of the cross-sectional area of the (1) psoas, (2) quadratus lumborum, (3) multifidus, and (4) erector spinae muscles in a patient before surgery. Cross-sectional area was the sum of area outlined in white.

(disability score ranged from 0 to $100: 0-20$ as mild, 20-40 as moderate, $40-60$ as severe, $60-80$ as very severe disability, and $80-100$ as bed-bound). As well, physical therapy was started 1 month after surgery, and both groups received similar therapy.

\section{Surgical Procedure}

After intubation in the supine position, the patient was placed in a prone position. After prep and drape, the skin was incised proper to anticipated levels of fusion. Deep dissection was performed to expose the posterior elements of the vertebral column. The pedicular screw was placed manually using $\mathrm{C}$-arm guidance under neuromonitoring. Multilevel laminectomy and foraminotomy plus discectomy were accomplished in some cases. After hemostasis, a combination of autologous and bone chips was inserted between transverse processes posterolaterally. A drain was affixed, and the wound was sutured in separate layers. Patients in both groups received the same anesthetic and surgical procedures.

\section{Statistical Methods}

Data analysis was performed using SPSS statistical software (version 21; SPSS, Inc, Chicago, IL). The normality of the data was assessed using the Kolmogorov-Smirnov test or histogram chart. Chi square or Fisher's exact test was used to compare qualitative variables between groups. Also, to compare the mean of quantitative variables between the studied groups, a $t$ test (if the variable distribution was normal) or Mann-Whitney test (if the variable distribution was abnormal) was used. The mean of quantitative variables with repetitive measures was done with repeated measure analysis of variance (ANOVA), two way ANOVA, and
Table 1. Characteristics of the patients.

\begin{tabular}{|c|c|c|c|}
\hline Variable & $\begin{array}{l}\text { Intervention } \\
(\mathrm{N}=40)\end{array}$ & $\begin{array}{c}\text { Control } \\
(\mathrm{N}=40)\end{array}$ & $\begin{array}{c}P \\
\text { Value }\end{array}$ \\
\hline Age, y & $49.43 \pm 8.79$ & $53.18 \pm 8.88$ & $.06^{\mathrm{a}}$ \\
\hline \multicolumn{4}{|l|}{ Gender, n (\%) } \\
\hline Female & $24(60)$ & $23(57.5)$ & \\
\hline Male & $16(40)$ & $17(42.5)$ & $.82^{\mathrm{b}}$ \\
\hline \multicolumn{4}{|l|}{ Osteopenic, n (\%) } \\
\hline No & $24(60)$ & $23(57.5)$ & \\
\hline Yes & $16(40)$ & $17(42.5)$ & $.82^{\mathrm{b}}$ \\
\hline Level of fusion, $\mathrm{n}(\%)$ & $4(2)$ & $4(1)$ & $.56^{\mathrm{c}}$ \\
\hline \multicolumn{4}{|l|}{ Cause of surgery, n (\%) } \\
\hline SS & $35(87.51)$ & $34(85)$ & $.74^{\mathrm{b}}$ \\
\hline $\mathrm{SL}$ & $5(12.5)$ & $6(15)$ & $.42^{\mathrm{b}}$ \\
\hline \multicolumn{4}{|c|}{$\mathrm{BMI}$, mean $\pm \mathrm{SD}, \mathrm{kg} / \mathrm{m}^{2}$} \\
\hline Baseline & $27.09 \pm 2.45$ & $26.76 \pm 2.07$ & \\
\hline 1 mo after surgery & $26.53 \pm 2.26$ & $26.92 \pm 2.157$ & $.35^{\mathrm{d}}$ (time) \\
\hline 3 mo after surgery & $26.38 \pm 2.19$ & $26.93 \pm 2.11$ & .68 (group) \\
\hline \multicolumn{4}{|l|}{ Food intake } \\
\hline Energy, kcal & $2056(730)$ & $2034.5(807)$ & $.82^{\mathrm{c}}$ \\
\hline Protein, g & $73.61 \pm 13.81$ & $70.56 \pm 12.05$ & $.29^{\mathrm{a}}$ \\
\hline Carbohydrate, $\mathrm{g}$ & $273.50 \pm 69.47$ & $298.55 \pm 52.38$ & $.07^{\mathrm{a}}$ \\
\hline Fat, g & $58.3(19.81)$ & $54.68(22.84)$ & $.82^{\mathrm{c}}$ \\
\hline Phosphorous, mg & $674.81 \pm 97.71$ & $640.17 \pm 120.52$ & $.16^{\mathrm{a}}$ \\
\hline Calcium, mg & $403.56 \pm 79.78$ & $407.58 \pm 78.98$ & $1^{\mathrm{a}}$ \\
\hline Zinc, mg & $6.41 \pm 0.81$ & $6.44 \pm 0.95$ & $.86^{\mathrm{a}}$ \\
\hline Magnesium, mg & $216.7(71.7)$ & $231.25(86.6)$ & $.18^{\mathrm{c}}$ \\
\hline vitamin $\mathrm{K}, \mu \mathrm{g}$ & $77.45(28.77)$ & $79.51(23.86)$ & $.82^{\mathrm{c}}$ \\
\hline vitamin $\mathrm{C}, \mathrm{mg}$ & $64.35 \pm 13.77$ & $68.28 \pm 9.24$ & $.13^{\mathrm{a}}$ \\
\hline
\end{tabular}

Abbreviations: BMI, body mass index; SD, standard deviation; SL, spondylolisthesis; SS, spinal stenosis.

${ }^{\mathrm{a}}$ Based on independent samples test (mean $\left.\pm \mathrm{SD}\right)$.

${ }^{\mathrm{b}}$ Based on $\chi^{2}$ tests, No. $(\%)$.

${ }^{\mathrm{c}}$ Based on Mann-Whitney $U$ tests, median (interquartile range).

${ }^{\mathrm{d}}$ Based on repeated measures analysis of variance (mean $\pm \mathrm{SD}$ ).

paired $t$ tests. In this study, the results were considered statistically significant at $P<.05$. Frequency distribution, mean \pm standard deviation, and median (interquartile range) are reported based on the type of variable.

\section{RESULTS}

\section{Patient Characteristics}

Of the 97 patients enrolled in the study, 17 patients were lost to follow up (Figure 1). Table 1 shows the demographic characteristics and the dietary intakes of the patients. At preoperation assessment, there was no significant difference between groups in terms of age, gender, BMI, BMD, cause of surgery, level of fusion, and dietary intake as well as energy, carbohydrate, fat, and vitamin $(\mathrm{C}$ and $\mathrm{K}$ ) intake. However, postoperative protein intake was higher than preoperative intake in both groups, and the intake of phosphorus, calcium, and zinc increased postoperation compared with before surgery, but did not differ between the 2 groups (Table 2). To eliminate the confounding factor and the difference in muscle volume between men and women, gender distribution was matched, 
Table 2. Summary of dietary intake.

\begin{tabular}{lccc}
\hline Variable & $\begin{array}{c}\text { Intervention } \\
(\mathbf{N}=\mathbf{4 0})^{\mathbf{a}}\end{array}$ & $\begin{array}{c}\text { Control } \\
(\mathbf{N}=\mathbf{4 0})^{\mathbf{a}}\end{array}$ & $\begin{array}{c}\boldsymbol{P} \\
\text { Value }\end{array}$ \\
\hline Protein, g/d & & & \\
Baseline & $70.61 \pm 5.81$ & $70.56 \pm 4.05$ & .09 (time), \\
$15 \mathrm{~d}$ after surgery & $84.47 \pm 3.62$ & $83.45 \pm 4.02$ & .52 (group) \\
1 mo after surgery & $87.10 \pm 3.02$ & $88.10 \pm 2.55$ & \\
3 mo after surgery & $88.90 \pm 2.10$ & $87.86 \pm 2.67$ & \\
Phosphorous, mg & & & \\
Baseline & $674.81 \pm 97.71$ & $640.17 \pm 120.52$ & $<.001$ (time), \\
$15 \mathrm{~d}$ after surgery & $715.42 \pm 39.69$ & $714.09 \pm 29.49$ & .10 (group) \\
1 mo after surgery & $728.63 \pm 17.51$ & $723.38 \pm 19.70$ & \\
3 mo after surgery & $716.73 \pm 13.74$ & $710.88 \pm 14.90$ & \\
Calcium, mg & & & \\
Baseline & $403.56 \pm 79.78$ & $407.58 \pm 78.98$ & $<.001$ (time), \\
$15 \mathrm{~d}$ after surgery & $570.49 \pm 67.02$ & $578.77 \pm 86.43$ & .33 (group) \\
1 mo after surgery & $573.96 \pm 86.43$ & $589.29 \pm 81.64$ & \\
3 mo after surgery & $576.46 \pm 66.67$ & $589.29 \pm 69.96$ & \\
Zinc, mg & & & \\
Baseline & $6.41 \pm 0.81$ & $6.44 \pm 0.95$ & $<.001$ (time), \\
$15 \mathrm{~d}$ after surgery & $10.24 \pm 1.87$ & $10.05 \pm 1.31$ & .25 (group) \\
1 mo after surgery & $9.92 \pm 1.60$ & $10.43 \pm 1.58$ & \\
3 mo after surgery & $9.96 \pm 1.52$ & $10.53 \pm 1.58$ & \\
\hline
\end{tabular}

${ }^{\mathrm{a}}$ Based on repeated measures analysis of variance (mean $\pm \mathrm{SD}$ ).

and the effect of this factor on the results of the study largely vanished $(P=.82)$.

\section{Assessment of Paraspinal Muscles CSA}

The CSAs of the muscles before and after surgery were assessed in both groups using thin-slice CT scan. Three months after surgery, there was a significant difference between the 2 groups in the left and right multifidus and psoas muscles. In the intervention group, an increase in muscle CSA was observed; in the control group, a decrease in the CSA of the corresponding muscles was seen, and this difference between the 2 groups was significant $(P<.001)$. A decrease in the volume of the right and left erector spinae and quadratus lumborum muscles was observed in both groups, with the decrease being greater in the control group. The difference between the 2 groups was significant in the right side $(P<.001)$ in contrast with the difference in the left side that was not significant $(P$ $=.11$; Figure. 3 ).

\section{Pain Assessment}

Table 3 shows that pain decreased over time in both groups after surgery, but the pain reduction in the intervention group was significantly higher than the control group up to 3 months after surgery (at the final point of follow up in this study; $P<.001$.
Table 3. Visual analog scale (VAS) assessment in intervention and control groups.

\begin{tabular}{lccc}
\hline VAS & $\begin{array}{c}\text { Intervention } \\
(\mathbf{N}=\mathbf{4 0})^{\mathbf{a}}\end{array}$ & $\begin{array}{c}\text { Control } \\
(\mathbf{N}=\mathbf{4 0})^{\mathbf{a}}\end{array}$ & $\begin{array}{c}\boldsymbol{P} \\
\text { Value }\end{array}$ \\
\hline Baseline & $8.10 \pm 1.33$ & $8.70 \pm 1.09$ & $<.001$ (time), \\
Time of discharge & $5.75 \pm 1.08$ & $6.65 \pm 0.86$ & $<.001$ (group) \\
15 d after surgery & $4.12 \pm 1.13$ & $5.22 \pm 1.02$ & \\
1 mo after surgery & $1.93 \pm 1.18$ & $4.20 \pm 0.72$ & \\
3 mo after surgery & $0.93 \pm 0.94$ & $3.10 \pm 1.03$ & \\
\hline
\end{tabular}

${ }^{a}$ Based on repeated measures analysis of variance (mean $\pm \mathrm{SD}$ ).

\section{Disability Assessment}

The decrease in ODI was significant in both groups over time after surgery $(P<.001)$, but in the intervention group, the amount of reduction was greater than the control group. Three months after surgery, in the intervention group, the average decreased from 28.3 to 8.45 , and in the control group from 29.8 to $13(P=.001$; Figure 4$)$.

\section{DISCUSSION}

Due to limited movement and bed rest after surgery, dietary intervention may be one of the few practical and easily managed options in this condition. This is the first clinical study, to our knowledge, to demonstrate that protein supplementation (at a dose of $36 \mathrm{~g} / \mathrm{d}$ for 4 weeks) reduced paraspinal muscle atrophy, pain, and disability after lumbar spine fusion in patients with multilevel canal stenosis and spondylolisthesis.

Many studies have investigated muscle atrophy and its consequences in catabolic conditions on patients such as intensive care unit and cancer patients as well as those with end-stage disease ${ }^{20}$; however, this association has been less studied in a large group of healthy people undergoing surgery. Physiologically, a muscle mass loss of $1 \%$ to $2 \%$ per year occurs after the age of $65 .^{21}$ Conditions such as diabetes, obesity, decrease in the level of physical

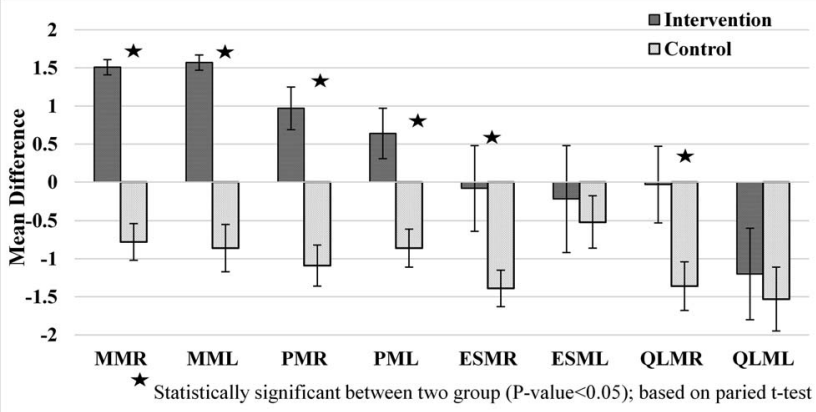

Figure 3. Changes in cross-sectional area of paraspinal muscles after 3 months. 


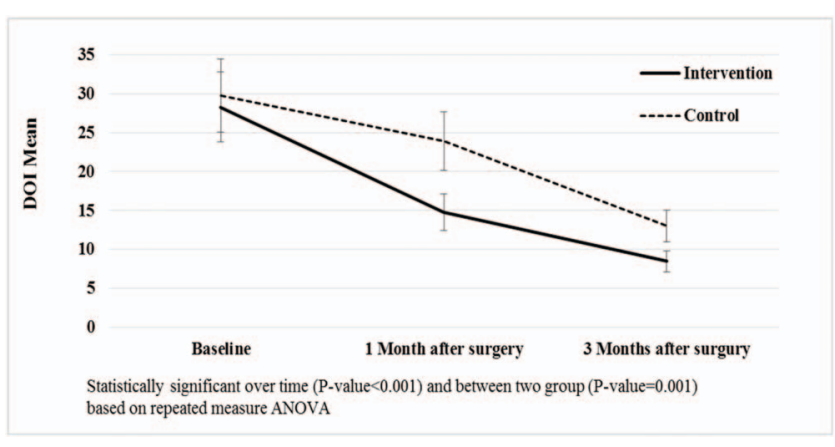

Figure 4. Oswestry disability index assessment in intervention and control groups.

activity, enforced bed rest, and reduced intake of nutrients (such as protein) that are effective in building muscle accelerate this process. ${ }^{22}$ More than 14 days of bed rest has been shown to reduce LBM in both young and old people. ${ }^{23,24} \mathrm{~A}$ recent study reported significant decrease of $1.1 \%$ to $4.2 \%$ in thigh muscle volume and $1.0 \%$ to $3.4 \%$ in quadriceps within 5 days after surgery. ${ }^{25}$ Tandon et $\mathrm{al}^{26}$ showed significant damage to the lumbar paraspinal muscles (a reduction in the CSA and denervation) after lumbar fusion surgery.

Studies have shown that protein synthesis and degradation are complex processes that are influenced by multiple signals and metabolic pathways. Two important signaling pathways for increasing protein synthesis are the mammalian target of rapamycin (mTOR) and insulin. The mTOR pathway is activated by essential amino acids and whole protein. Hormone insulin increases protein synthesis by stimulating $\mathrm{mTOR}$ and increases the transport of amino acids into muscle; insulin also has an inhibitory effect on protein breakdown. ${ }^{27-29}$ One of the most important signals of protein degradation is reactive oxygen species (ROS). ${ }^{30}$ When ROS formation exceeds the ability of glutathione to neutralize them, increased protein degradation occurs. Muscle degradation begins before surgery with inhibition of the mTOR pathway and increased oxidative stress and continues after surgery with increased insulin resistance, decreased amino acid levels, and reduced glutathione. ${ }^{31-33}$

It has been shown that presurgery and postsurgery protein administration with mTOR pathway stimulation, oxidative stress inhibition, and decreased insulin resistance results in increased glutathione and insulin amino acid transfer that prevents $20 \%$ to $40 \%$ of postoperative muscle atrophy. ${ }^{14,34,35}$

In the current study, paraspinal muscle atrophy 3 months after surgery was much lower in the protein supplement group than in the placebo group. The multifidus muscle, as part of the group of slowtwitch muscles, is the innermost paraspinal lumbar muscle and very sensitive to injury. ${ }^{36}$ In the group receiving the protein supplement, there was an increase in the volume of this muscle. In the same way, the volume of the psoas muscle, which is the largest muscle in the lower cross section of the lumbar spine and strengthens the spine, ${ }^{37}$ increased in the intervention group compared with the control group.

In contrast, the volume of the right erector spinae and quadratus lumborum muscles decreased in both groups. The erector spinae are not just 1 muscle, but a group of muscles and tendons that runs more or less the length of the spine on the left and the right, from the sacral region and hips to the base of the skull. Because they have a longer lever arm than the multifidus muscle, most of the movement of the trunk extensor muscles is produced by these muscles instead of the multifidus muscle. ${ }^{10}$ The quadratus lumborum muscle is markedly smaller than the dorsal extensor muscles, but because of the way it connects, it plays an important role in lumbopelvic movements and especially in vertebral stability. ${ }^{38}$ Paddon-Jones et $\mathrm{al}^{39}$ showed that essential amino acid supplementation decreased the loss of lean muscle mass during 28 days of bed rest. They further demonstrated that supplementation with 15 g essential amino acids stimulated muscle protein synthesis in healthy young and elderly individuals after $12-15$ hours of bed rest. ${ }^{40}$

It seems that protein supplementation, in addition to affecting synthesis and breakdown pathways, reduces atrophy that results in greater pain reduction after surgery in the intervention group. In several studies, the relationship between pain and muscle atrophy has been observed, and the most important and most common cause of chronic mechanical pain is muscle atrophy. ${ }^{38,41}$ In the same way, muscle atrophy is associated with disability. ${ }^{42}$ Reducing disability is one of the main goals of postoperative rehabilitation. Tarnanen et $\mathrm{al}^{43}$ showed that changes in ODI scores were associated with changes in muscle strength, and increased muscle strength reduced disability in patients after lumbar spine fusion. The current study showed that the rate of disability was more greatly reduced in people receiving protein supplementation than in the control group. 
This study has 2 limitations. First, with CT images, it was impossible to accurately measure CSA at fusion level due to the artificial signal caused by the screws. Thus, CSA was measured at the lowest level above the fused segments to eliminate metal artifacts. Second, the sample size was somewhat small. Studies with a larger sample size and longer follow up are needed to confirm the beneficial effects of protein supplementation in paraspinal muscles of patients who undergo spinal fusion surgery.

\section{CONCLUSIONS}

In conclusion, this clinical study is the first study, to our knowledge, to demonstrate that protein supplementation significantly prevented paraspinal muscle atrophy and reduced pain and disability after spinal fusion surgery. It is recommended that protein supplementation be considered as a complementary method to improve outcomes in spinal fusion surgery.

\section{REFERENCES}

1. Jordan JL, Konstantinou K, O'Dowd J. Herniated lumbar disc. BMJ Clin Evid. 2011;2011:1118.

2. Fineberg SJ, Nandyala SV, Kurd MF, et al. Incidence and risk factors for postoperative ileus following anterior, posterior, and circumferential lumbar fusion. Spine J. 2014;14(8):16801685 .

3. Fardon DF, Milette PC. Nomenclature and classification of lumbar disc pathology: recommendations of the combined task forces of the North American Spine Society, American Society of Spine Radiology, and American Society of Neuroradiology. Spine. 2001;26(5):E93-E113.

4. Kim K-T, Lee S-H, Lee Y-H, Bae S-C, Suk K-S. Clinical outcomes of 3 fusion methods through the posterior approach in the lumbar spine. Spine. 2006;31(12):1351-1357.

5. Helenius I, Remes V, Yrjönen T, et al. Comparison of long-term functional and radiologic outcomes after Harrington instrumentation and spondylodesis in adolescent idiopathic scoliosis: a review of 78 patients. Spine. 2002;27(2):176-180.

6. Leong J, Chun S, Grange W, Fang D. Long-term results of lumbar intervertebral disc prolapse. Spine. 1983;8(7):793799.

7. Luk K, Lee F, Leong J, Hsu L. The effect on the lumbosacral spine of long spinal fusion for idiopathic scoliosis. A minimum 10-year follow-up. Spine. 1987;12(10):996-1000.

8. Motosuneya $\mathrm{T}$, Asazuma $\mathrm{T}$, Tsuji $\mathrm{T}$, Watanabe $\mathrm{H}$, Nakayama Y, Nemoto K. Postoperative change of the crosssectional area of back musculature after 5 surgical procedures as assessed by magnetic resonance imaging. J Spinal Disord Tech. 2006;19(5):318-322.

9. Kim K-T, Lee S-H, Suk K-S, Bae S-C. The quantitative analysis of tissue injury markers after mini-open lumbar fusion. Spine. 2006;31(6):712-716.

10. Lee HJ, Lim WH, Park J-W, et al. The relationship between cross sectional area and strength of back muscles in patients with chronic low back pain. Ann Rehabil Med. 2012;36(2):173-181.

11. Helgeson MD, Bevevino AJ, Hilibrand AS. Update on the evidence for adjacent segment degeneration and disease. Spine J. 2013;13(3):342-351.

12. Gillet P. The fate of the adjacent motion segments after lumbar fusion. J Spinal Disord Tech. 2003;16(4):338-345.

13. Waschke A, Hartmann C, Walter J, et al. Denervation and atrophy of paraspinal muscles after open lumbar interbody fusion is associated with clinical outcome - electromyographic and CT-volumetric investigation of 30 patients. Acta Neurochir (Wien). 2014;156(2):235-244.

14. Portman R. Method to reduce muscle atrophy following orthopedic surgery. Google Patents; July 13, 2017.

15. Remes V, Lamberg T, Tervahartiala P, et al. Long-term outcome after posterolateral, anterior, and circumferential fusion for high-grade isthmic spondylolisthesis in children and adolescents: magnetic resonance imaging findings after average of 17-year follow-up. Spine. 2006;31(21):2491-2499.

16. Shils ME, Olson JA, Shike M, eds. Modern Nutrition in Health and Disease. 8th ed. Philadelphia, PA: Lea \& Febiger; 1994.

17. Kim D-Y, Lee S-H, Chung SK, Lee H-Y. Comparison of multifidus muscle atrophy and trunk extension muscle strength: percutaneous versus open pedicle screw fixation. Spine. 2005;30(1):123-129.

18. Hu Z-J, He J, Zhao F-D, Fang X-Q, Zhou L-N, Fan SW. An assessment of the intra-and inter-reliability of the lumbar paraspinal muscle parameters using CT scan and magnetic resonance imaging. Spine. 2011;36(13):E868-E874.

19. Yoo J-S, Min S-H, Yoon S-H, Hwang C-H. Paraspinal muscle changes of unilateral multilevel minimally invasive transforaminal interbody fusion. $J$ Orthop Surg Res. 2014;9:130. doi:10.1186/s13018-014-0130-3

20. Puthucheary ZA, Rawal J, McPhail M, et al. Acute skeletal muscle wasting in critical illness. JAMA. 2013;310(15):1591-1600.

21. Van Kan GA. Epidemiology and consequences of sarcopenia. J Nutr Health Aging. 2009;13(8):708-712.

22. Van Ancum JM, Scheerman K, Pierik VD, et al. Muscle strength and muscle mass in older patients during hospitalization: The EMPOWER study. Gerontology. 2017;63(6):507-514.

23. Pišot R, Marusic U, Biolo G, et al. Greater loss in muscle mass and function but smaller metabolic alterations in older compared with younger men following 2 wk of bed rest and recovery. J Appl Physiol. 2016;120(8):922-929.

24. Biolo G, Pišot R, Mazzucco S, et al. Anabolic resistance assessed by oral stable isotope ingestion following bed rest in young and older adult volunteers: elationships with changes in muscle mass. Clin Nutr. 2017;36(5):1420-1426.

25. Kouw IW, Groen BB, Smeets JS, et al. One week of hospitalization following elective hip surgery induces substantial muscle atrophy in older patients. $J$ Am Med Dir Assoc. 2019;20(1):35-42.

26. Tandon R, Kiyawat V, Kumar N. Clinical correlation between muscle damage and Oswestry Disability Index score after open lumbar surgery: does open surgery reduces functional ability? Asian Spine J. 2018;12(3):518-523.

27. Fujita S, Dreyer HC, Drummond MJ, et al. Nutrient signalling in the regulation of human muscle protein synthesis. $J$ Physiol. 2007;582(2):813-823. 
28. Bar-Peled L, Sabatini DM. Regulation of mTORC1 by amino acids. Trends Cell Biol. 2014;24(7):400-406.

29. Jackman RW, Kandarian SC. The molecular basis of skeletal muscle atrophy. Am J Physiol Cell Physiol. 2004;287(4):C834-C843.

30. Perrone F, da-Silva-Filho AC, Adôrno IF, et al. Effects of preoperative feeding with a whey protein plus carbohydrate drink on the acute phase response and insulin resistance. A randomized trial. Nutr J. 2011;10:66. doi:10.1186/1475-2891-10-66

31. Kimball S, Farrell PA. Exercise effects on muscle insulin signaling and action invited review: role of insulin in translational control of protein synthesis in skeletal muscle by amino acids or exercise. J Appl Physiol. 2002;93(3):1168-1180.

32. Patel J, McLeod LE, Vries RG, Flynn A, Wang X, Proud CG. Cellular stresses profoundly inhibit protein synthesis and modulate the states of phosphorylation of multiple translation factors. Eur J Biochem. 2002;269(12):3076-3085.

33. Powers SK, Smuder A, Judge A. Oxidative stress and disuse muscle atrophy: cause or consequence? Curr Opin Clin Nutr Metab Care. 2012;15(3):240-245.

34. Del Savio GC, Zelicof SB, Wexler LM, et al. Preoperative nutritional status and outcome of elective total hip replacement. Clin Orthop Relat Res. 1996;326:153-161. doi:10.1097/00003086-199605000-00018

35. Paddon-Jones D, Rasmussen BB. Dietary protein recommendations and the prevention of sarcopenia: protein, amino acid metabolism and therapy. Curr Opin Clin Nutr Metab Care. 2009;12(1):86-90.

36. Kim CW. Scientific basis of minimally invasive spine surgery: prevention of multifidus muscle injury during posterior lumbar surgery. Spine. 2010;35(26S):S281-S286.

37. Kim WH, Lee S-H, Lee DY. Changes in the crosssectional area of multifidus and psoas in unilateral sciatica caused by lumbar disc herniation. J Korean Neurosurg Soc. 2011;50(3):201-204.

38. Barker KL, Shamley DR, Jackson D. Changes in the cross-sectional area of multifidus and psoas in patients with unilateral back pain: the relationship to pain and disability. Spine. 2004;29(22):E515-E519.

39. Paddon-Jones D, Sheffield-Moore M, Urban RJ, et al. Essential amino acid and carbohydrate supplementation ameliorates muscle protein loss in humans during 28 days bedrest. J Clin Endocrinol Metab. 2004;89(9):4351-4358.
40. Paddon-Jones D, Sheffield-Moore M, Zhang X-J, et al. Amino acid ingestion improves muscle protein synthesis in the young and elderly. Am $J$ Physiol Endocrinol Metab. 2004;286(3):E321-E328.

41. Kang C, Shin M, Kim S, Lee S, Lee C-S. MRI of paraspinal muscles in lumbar degenerative kyphosis patients and control patients with chronic low back pain. Clin Radiol. 2007;62(5):479-486.

42. Fan S, Hu Z, Zhao F, Zhao X, Huang Y, Fang X. Multifidus muscle changes and clinical effects of one-level posterior lumbar interbody fusion: minimally invasive procedure versus conventional open approach. Eur Spine $J$. 2010;19(2):316-324.

43. Tarnanen S, Neva MH, Kautiainen H, et al. The early changes in trunk muscle strength and disability following lumbar spine fusion. Disabil Rehabil. 2013;35(2):134-139.

Disclosures and COl: The authors declare that they have no known competing financial interests or personal relationships that could have appeared to influence the work reported in this paper. Trial registration: ClinicalTrials.gov identifier: NCT04300517.

Corresponding Author: Saeed Oraee-Yazdani, MD, Functional Neurosurgery Research Center, Shohada Tajrish Comprehensive Neurosurgical Center of Excellence, Shahid Beheshti University of Medical Sciences, P.O. Box 1988873554, Tehran, Iran. Phone: 00982122718003 ; Email: Saeed_o_yazdani@sbmu.ac.ir.

Published 26 February 2021

This manuscript is generously published free of charge by ISASS, the International Society for the Advancement of Spine Surgery. Copyright (C) 2021 ISASS. To see more or order reprints or permissions, see http://ijssurgery.com. 